\title{
Duodenal Gastrinomas, Duodenotomy, and Duodenal Exploration in the Surgical Management of Zollinger-Ellison Syndrome
}

\author{
Norman W. Thompson, M.D., Janice Pasieka, M.D., and Atsushi Fukuuchi, M.D. \\ Department of Surgery, University of Michigan Medical Center, Ann Arbor, Michigan, U.S.A.
}

\begin{abstract}
Studies have shown that the duodenum is a more common site $(30-40 \%)$ of primary gastrinomas than previously reported. These tumors are often occult to conventional exploration, and their detection requires duodenotomy and meticulous evaluation of the mucosa by eversion and direct palpation. Furthermore, tumors as small as 1 to $2 \mathrm{~mm}$ may be associated with lymph node metastases. Seven patients with duodenal gastrinomas treated during a 2-year period are reported. Four had sporadic ZollingerEllison syndrome (ZES), and three had multiple endocrine neoplasia type I (MEN-I) syndrome. All seven patients had malignant duodenal gastrinomas as proved by metastatic lymph nodes and in one case a large liver metastasis as well. Local excision of the tumor, lymph node excisions, and in one case liver lobectomy resulted in eugastrinemia in the 4 with sporadic ZES. Two of the three with MEN-I were also eugastrinemic after similar procedures, with the addition of distal pancreatectomy. Duodenotomy is considered an essential procedure in sporadic ZES patients when no pancreatic tumor is found and in all MEN-I/ZES patients, regardless of the pancreatic findings. Regional lymph node excisions are essential when a duodenal tumor has been found.
\end{abstract}

At one time it was assumed that most patients with ZollingerEllison syndrome (ZES) had malignant pancreatic tumors with metastases that precluded a curative surgical resection. Therefore nearly all patients were treated by total gastrectomy with the exception of a few with primary extrapancreatic tumors [1, 2]. Once drugs became available that adequately controlled gastric acid hypersecretion, more emphasis was placed on identifying ZES patients who were potentially curable by tumor resection. Currently, it is estimated that up to $40 \%$ of patients with sporadic ZES have tumors that can be successfully resected [3]. These patients have primary tumors arising in the pancreas or duodenum with or without regional lymph node spread but no liver metastases. However, during the past decade, as many as $40 \%$ of patients proved biochemically to have ZES who have undergone exploration have had negative findings [4]. As a result, these patients were subsequently treated with drug therapy or had palliative surgical procedures such as selective vagotomy or even total gastrectomy. Furthermore, in most centers, multiple endocrine neoplasia type I (MEN-I)/ZES patients have been treated by drugs without

Offprint requests: N.W. Thompson, M.D., University of Michigan Medical Center, 2920 Taubman Center, Box 0331, 1500 East Medical Center Drive, Ann Arbor, Michigan 48109-0331, U.S.A. exploration because of the assumption that, short of total pancreatectomy, their hypergastrinemia could not be controlled surgically [5]. Our experience during the last 10 years, during which time transhepatic selective venous sampling for gastrin (TSVS) was used to regionalize the source of gastrin secretion, convinced us that small duodenal tumors (microadenomas) could easily be overlooked during a standard exploration and thus be the cause of a failed procedure $[4,6]$. Recent studies have shown that the duodenum is a more common site of primary gastrinomas than previously thought [7-11]. It is currently estimated that between $30 \%$ and $40 \%$ of patients with sporadic ZES have duodenal tumors and that nearly all MEN-I patients with ZES have duodenal primary tumors with or without additional pancreatic neuroendocrine neoplasms [7]. In 1989 we reported our experience with 5 patients with microgastrinomas of the duodenum that were occult to conventional exploration for ZES [4]. In each case, a duodenotomy was required for their identification. Despite their small size $(2 \mathrm{~mm})$, these tumors were considered the sole source of hypergastrinemia and were locally excised for cure. The tumors could not be palpated through the bowel wall and were found and visualized only after a duodenotomy and a meticulous evaluation of the mucosa by eversion and direct palpation. Preoperative TSVS for gastrin directed attention to the duodenum or head of the pancreas as a source of hypergastrinemia in each of these cases. Despite their small size, two of these tumors were associated with small metastatic lymph nodes. As a result of this experience, duodenotomy and intraluminal exploration became essential maneuvers to be used in any operation for sporadic ZES patients when no tumor was found within the pancreas and routine components of any exploration in MEN-I/ZES patients, regardless of the pancreatic findings. Furthermore, because primary duodenal gastrinomas as small as $2 \mathrm{~mm}$ had been proved to metastasize to local nodes, excision of all peripancreatic nodes in the region of a duodenal primary tumor was also considered essential.

During the past 2 years, an additional 7 patients with duodenal gastrinomas were treated at the University of Michigan Medical Center (UMMC). The purpose of this paper is to describe their management and the results of surgical therapy. Four of these patients had sporadic ZES, and three were 


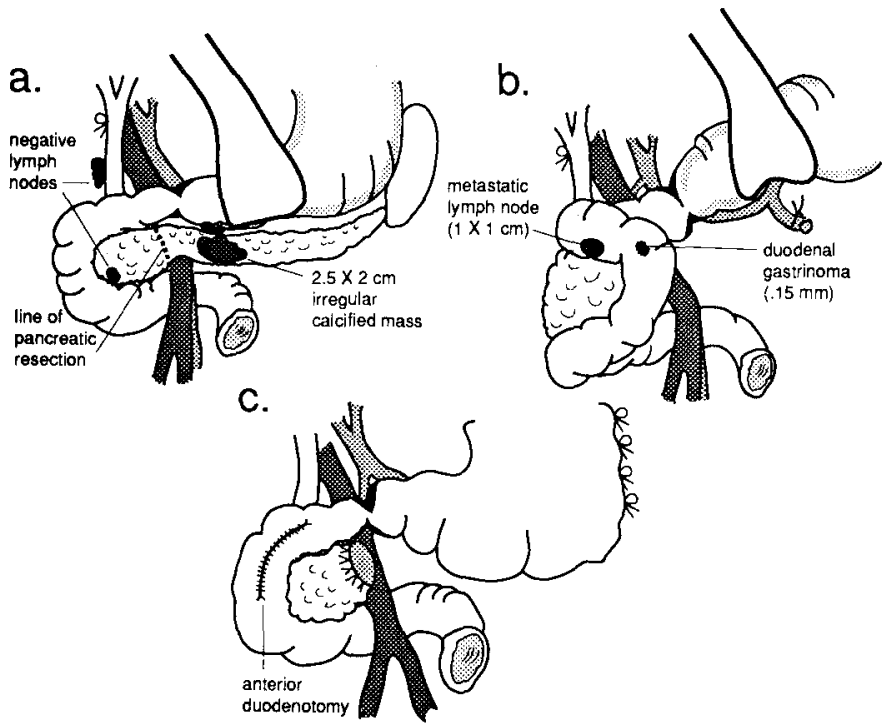

Fig. 1. Case 1: sporadic ZES in a 54-year-old woman.

patients with MEN-I syndrome in which ZES was a component.

\section{Patient Summaries: Sporadic ZES}

\section{Case 1}

A 54-year-old woman presented with a 6-year history of peptic ulcer disease consisting of abdominal pain and upper gastrointestinal (GI) bleeding. She also had a 2-year history of diarrhea and episodes of recurrent pancreatitis thought to be alcoholrelated. She was admitted to an outside hospital for pancreatitis and on investigation was found to have multiple gastric and duodenal ulcers. Her serum gastrin level was $650 \mathrm{pg} / \mathrm{ml}$ and when stimulated with secretin rose to $1796 \mathrm{pg} / \mathrm{ml}$. A CT scan showed a $3 \mathrm{~cm}$ calcified mass in the neck of the pancreas. After transfer to UMMC, a selective arterial secretin injection study (SASI) was performed, which regionalized a gastrin-producing tumor in the pancreatic-duodenal region.

At exploration, a $3 \mathrm{~cm}$ calcified mass was found in the neck of the pancreas (Fig. 1). The remaining pancreas felt perfectly normal on complete exploration. After the pancreatic head and duodenum were mobilized, a $1 \mathrm{~cm}$ posterior pancreatic lymph node was found and excised. It was positive for metastatic neuroendocrine tumor. Through an anterior duodenotomy, a $0.15 \mathrm{~cm}$ neuroendocrine tumor was locally excised from the second part of the duodenum. Other peripancreatic and periduodenal lymph nodes were removed, but none was found to be positive for metastatic disease. A distal pancreatectomy was then performed for removal of the $3 \mathrm{~cm}$ lesion in the neck region. It was found to be a calcified cystic nodule with no neuroendocrine component. Immunohistochemical staining of the duodenal tumor and lymph node were positive for gastrin. The patient did well postoperatively and was discharged 7 days later. Her serum gastrin level 4 months later while on no medication was $80 \mathrm{pg} / \mathrm{ml}$, and a secretin stimulation study showed no rise in gastrin levels. She remains asymptomatic and requires no medication 18 months after operation.
Comments. This patient with sporadic ZES was found to have a microgastrinoma $1.5 \mathrm{~mm}$ in diameter that was undetectable until her duodenostomy was performed. Despite the small size of this neuroendocrine tumor, a single node on the posterior surface of the pancreas near the duodenum contained metastatic disease. Despite having only a local excision of primary tumor and lymph nodes, both basal and secretin-stimulated gastrin are normal; and for the present time she represents a biochemical "cure."

\section{Case 2}

A 53-year-old man had a long-standing history of peptic ulcer disease complicated by a perforated duodenal ulcer in 1974, which was treated by simple closure. Because of persistent ulcer symptoms, he underwent a partial gastrectomy and Billroth II procedure in 1982. His symptoms persisted; and in 1988, while on $\mathrm{H}_{2}$ antagonists, he presented with bleeding jejunal ulcers and a perforation. At that time he underwent a more extensive gastric resection and vagotomy with a Roux-en-Y anastomosis. In 1990 he presented to an outside hospital with severe esophagitis and a $1 \mathrm{~cm}$ bleeding marginal ulcer. While undergoing investigation he perforated his esophagus and required open drainage of the right chest, revision of his gastrojejunostomy, and insertion of a feeding jejunostomy tube. Serum gastrin levels were measured and found to be elevated. After his recovery, he was transferred to the UMMC for further evaluation. His basal serum gastrin level was $760 \mathrm{pg} / \mathrm{ml}$ and rose to $1700 \mathrm{pg} / \mathrm{ml}$ after secretin stimulation. Angiograms revealed a tumor blush in the region of the pancreatic head. Both TSVS for gastrin and SASI results were consistent with gastrin hypersecretion from the region of the pancreatic head or duodenum. At exploration, a $0.5 \mathrm{~cm}$ nodule was palpable in the duodenum just distal to his duodenal stump closure (Fig. 2). A duodenotomy was performed, and the lesion was excised with an ellipse of full-thickness duodenal wall. A $4 \mathrm{~mm}$ lymph node on the anterior surface of the pancreas next to the duodenum was excised that contained metastatic neuroendocrine tumor. All other peripancreatic lymph nodes were negative. Immunohistochemical staining of the duodenal tumor and adjacent metastatic lymph node were positive for gastrin. Postoperatively, he did well and was discharged from the hospital 7 days later. Because of his previous esophageal perforation, he was continued on omeprazole for 5 months after operation during which time his serum gastrin levels were slightly elevated. Subsequent to discontinuing the omeprazole, his serum gastrin levels have remained in the normal range, but he has not yet had a secretin stimulation test.

Comments. This patient with a 17-year history of complicated peptic ulcer disease was found to have a $0.5 \mathrm{~cm}$ primary gastrinoma in the duodenal wall, $1 \mathrm{~cm}$ distal to a closure of the duodenal stump 9 years before. The primary tumor, like others larger than $0.5 \mathrm{~cm}$, was locally invasive in the muscularis and could not be locally excised from the submucosa. The involved lymph node in this case was normal in size and would not have been identified as metastatic without microscopic confirmation. 


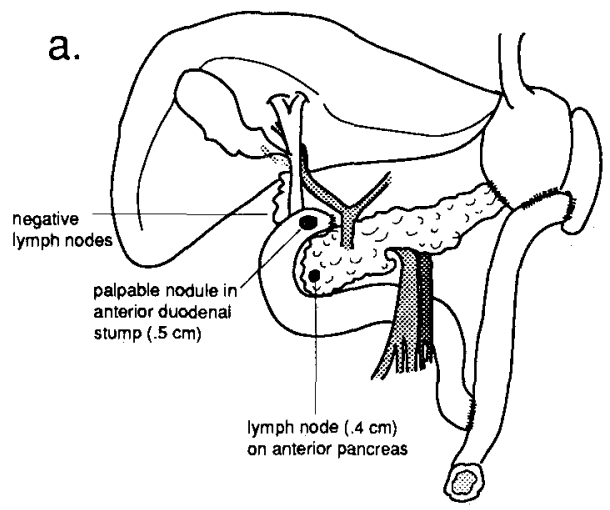

b.

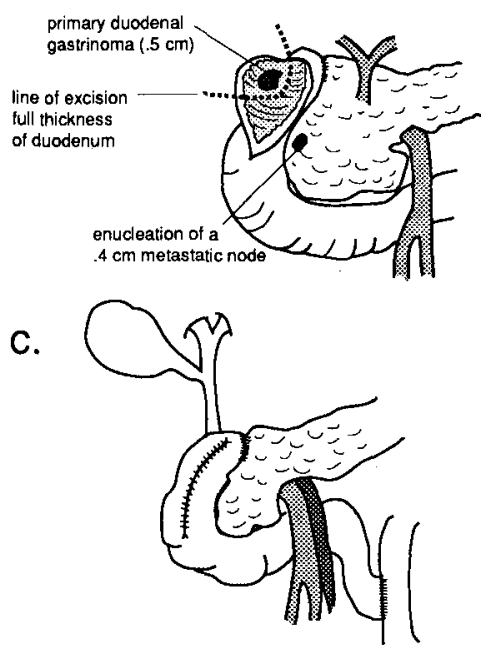

Fig. 2. Case 2: sporadic ZES in a 53-year-old man.

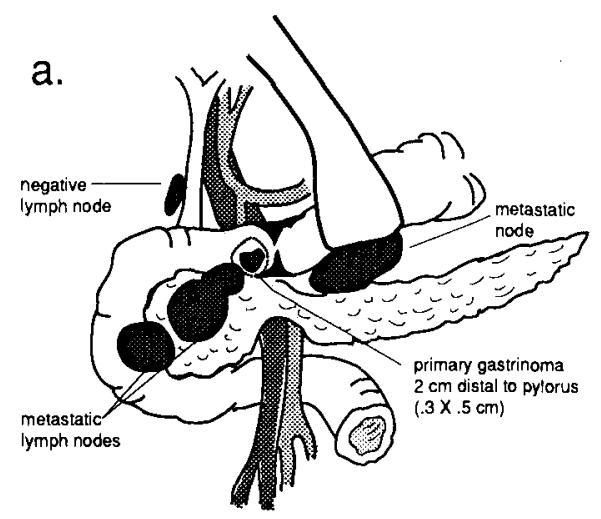

b.

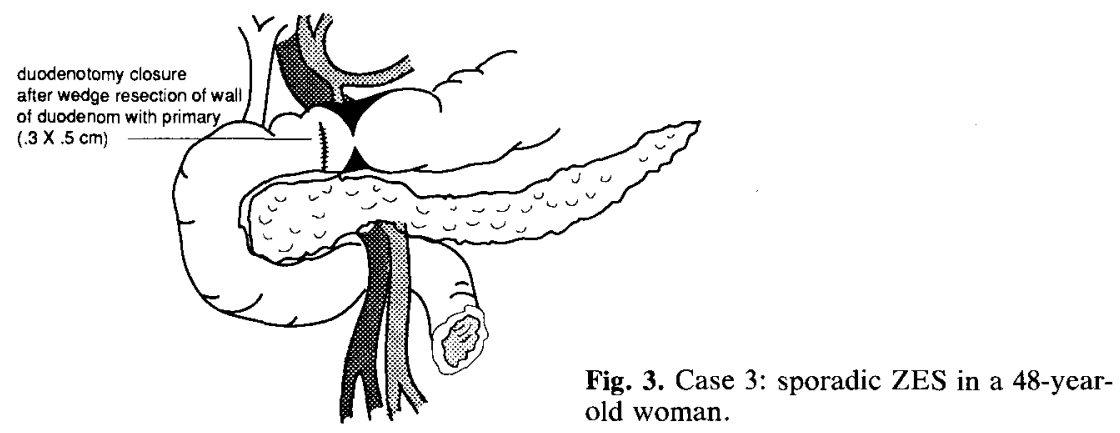

Case 3

A 48-year-old woman presented to the UMMC with a 10-year history of peptic ulcer disease. Despite treatment with cimetidine, she had complained of increasing abdominal pain and intermittent diarrhea for the past 2 years. On investigation, her basal serum gastrin level was $9900 \mathrm{pg} / \mathrm{ml}$ and rose to 15,000 $\mathrm{pg} / \mathrm{ml}$ after secretin stimulation. An angiogram revealed two areas of hypervascularity in the region of the pancreatic head. Both TSVS and SASI regionalized the source of the gastrin to the head of the pancreas or duodenum. At exploration, no primary tumor was found in the head of the pancreas, but four enlarged metastatic lymph nodes were found along the upper edge of the pancreatic head as well as one behind the pylorus (Fig. 3). A duodenostomy was performed and a $0.5 \times 0.3 \mathrm{~cm}$ submucosal lesion was found just distal to the pylorus. This lesion was excised with a full-thickness ellipse of duodenal wall and proved to be a neuroendocrine tumor by microscopic study. Postoperatively, the patient did well and was discharged 7 days later. Her serum gastrin level fell to $104 \mathrm{pg} / \mathrm{ml}$ while still on omeprazole. Six months later, after discontinuing the drug, her serum gastrin levels were normal $(95 \mathrm{pg} / \mathrm{ml})$.
Comments. This patient with a 10 -year history of ulcer disease and a 2-year history of diarrhea was evaluated for ZES because of intractable symptoms while on $\mathbf{H}_{2}$-blockers. Her primary tumor of $0.5 \mathrm{~cm}$ was locally invasive in the muscularis and was associated with lymph node metastases that were much larger than the primary tumor. Excision of the primary tumor after it was identified through the duodenostomy and regional lymph node dissection has normalized her serum gastrin level. She is asymptomatic and on no drugs.

\section{Case 4}

A 38-year-old male physician had a 2-week history of right upper quadrant pain and tenderness. Ultrasonography was performed and revealed a normal gallbladder but a $12 \mathrm{~cm}$ mass in the right lobe of the liver. A CT scan confirmed it, and a percutaneous needle biopsy was performed at an outside hospital. It identified a neuroendocrine tumor that stained positive for gastrin. A serum gastrin level was obtained and was 3800 $\mathrm{pg} / \mathrm{ml}$. He was placed on sandistatin and omeprazole, and was seen in consultation at several medical centers; recommendations ranged from liver transplantation to a Whipple procedure 
a.

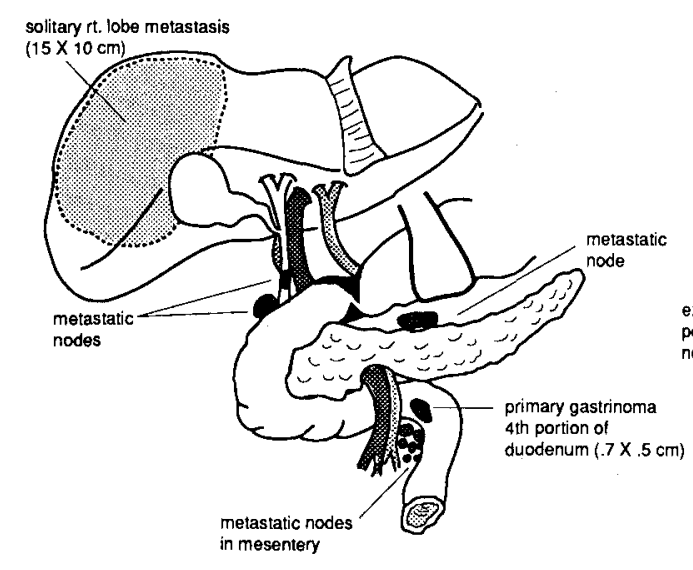

b.

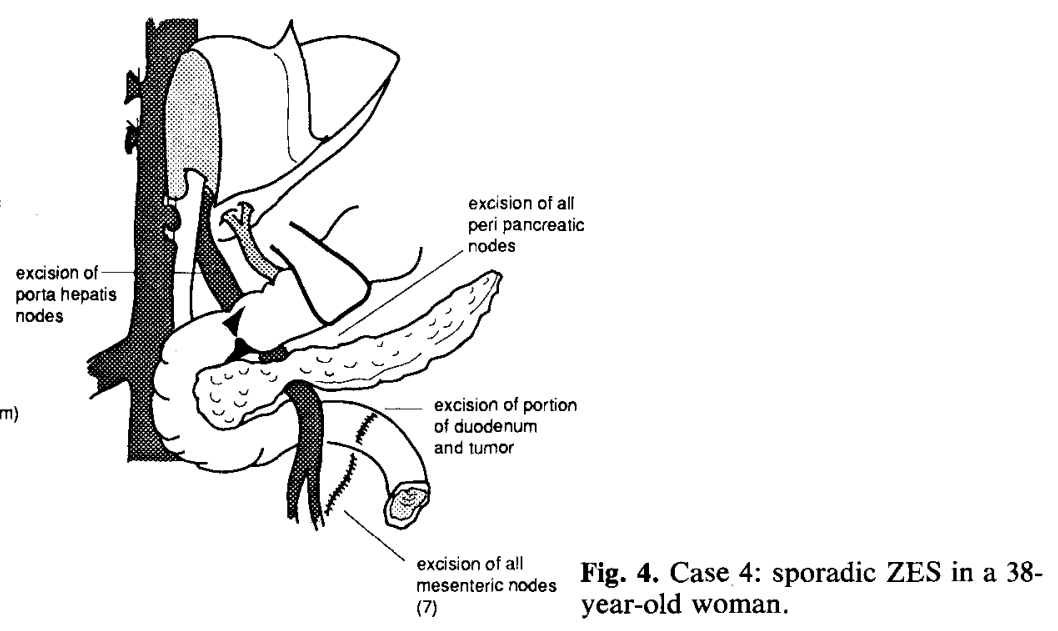

and right hepatic lobectomy. After being evaluated at the UMMC he underwent a TSVS and SASI in an attempt to localize the primary tumor. These studies, however, suggested that the liver tumor might be the only source of gastrin, but they were difficult to interpret because the basal gastrin level was so elevated $(18,000 \mathrm{pg} / \mathrm{ml})$. The patient elected to undergo an operation at the UMMC, and at exploration a single large metastasis $(15 \mathrm{~cm})$ was confined to the right lobe of the liver (Fig. 4). A right hepatic lobectomy was performed. Lymph nodes were excised from the hepatoduodenal ligament along the common bile duct and were found positive for neuroendocrine tumor. Palpation of the pancreas failed to reveal a tumor, and palpation of the first three parts of the duodenum were also negative. However, several firm lymph nodes were found in the mesentery of the fourth portion of the duodenum, and a nodule was palpable in the duodenal wall at its junction with the proximal jejunum. Duodenotomy was performed in the fourth portion of the duodenum, and a $0.7 \mathrm{~cm}$ submucosal nodule was excised with a full-thickness ellipse of duodenal wall. The local mesenteric lymph nodes were excised, as were all nodes along the superior mesenteric vein to the region of the neck of the pancreas as well as above the pancreas from celiac axis to the hepatic hilum. The final histopathologic report revealed that the primary duodenal gastrinoma, nine metastatic lymph nodes, and the hepatic metastasis all stained positive for gastrin.

Postoperatively, he did well and was discharged from the hospital 14 days later. His serum gastrin levels were normal during the early postoperative period $(42-60 \mathrm{pg} / \mathrm{ml})$, and all medications were discontinued. Five months after his surgery, his gastrin level was $87 \mathrm{pg} / \mathrm{ml}$ and a follow-up CT scan showed a hypertrophied left lobe of the liver (regeneration) with no evidence of metastatic disease; a secretin stimulation test was normal.

Comments. This patient with a duodenal gastrinoma is the only one we have seen with a liver metastasis. Although large, it was a solitary metastasis, and a right lobectomy completely removed the lesion. The primary tumor was in the fourth portion of the duodenum, and regional dissection of involved lymph nodes required excision of a portion of the mesentery, nodes along the superior mesenteric vein, and those above the neck of the pancreas to the hilum of the liver. Despite the extent of his disease, all gross tumor could be removed, resulting in eugastrinemia and an asymptomatic patient with an intact stomach. On the basis of normal basal and secretin-stimulated gastrin levels, he is currently considered a biochemical as well as clinical "cure" 8 months after operation.

\section{MEN-I/ZES}

\section{Case 5}

A 35-year-old woman was first seen at the UMMC complaining of a 2-year history of abdominal pain and diarrhea that required hospitalization on several occasions for dehydration. Thirteen years previously she had undergone a parathyroidectomy for what was described as a parathyroid "adenoma." She had been placed on cimetidine without relief, but omeprazole did control her symptoms. Evaluation consisted of a basal serum gastrin level of $3790 \mathrm{pg} / \mathrm{ml}$ rising to $9000 \mathrm{pg} / \mathrm{ml}$ after secretin stimulation. A CT scan showed a $3.5 \mathrm{~cm}$ lesion in the body of the pancreas and a $2.5 \mathrm{~cm}$ lesion in the region of the uncinate process. An angiogram showed corresponding lesions in these locations that were vascular. TSVS and SASI studies regionalized a gastrin-producing tumor to the head of the pancreas or duodenum. At exploration, the two pancreatic tumors previously identified were readily palpated (Fig. 5). A distal pancreatectomy, preserving the spleen, was performed, and the $2.5 \mathrm{~cm}$ tumor in the uncinate process was easily enucleated. Several enlarged lymph nodes along the common bile duct and in the peripancreatic region were excised and found to contain metastatic neuroendocrine tumor. A duodenotomy was then performed, and two duodenal submucosal neuroendocrine tumors were found in the second part of the duodenum. These lesions were excised with a full-thickness ellipse of duodenal wall and were found to be $1 \times 1 \mathrm{~cm}$ and $0.5 \times 0.7 \mathrm{~cm}$. Immunohisto- 

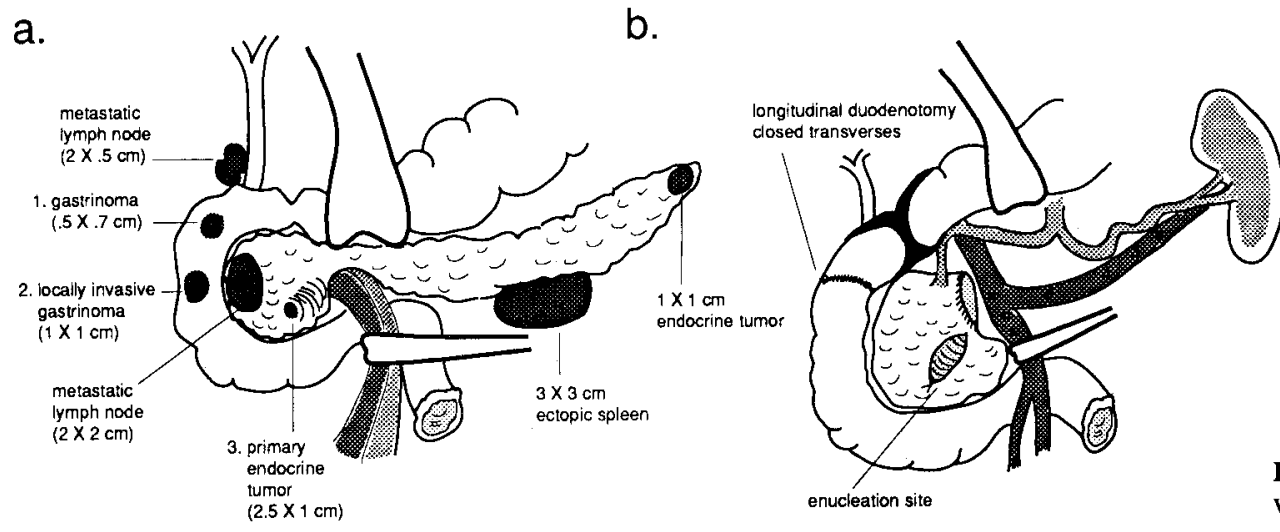

Fig. 5. Case 5: MEN-I in a 35-year-old woman.

chemical studies show that the uncinate tumor and both duodenal tumors were positive for gastrin, as were all lymph nodes containing metastases. The neuroendocrine tumor in the tail of the pancreas was negative for gastrin. The large tumor in the body was an ectopic spleen. Her postoperative course was complicated by a small pancreatic fistula and a wound infection. She was continued on omeprazole $20 \mathrm{mg} / \mathrm{day}$, and her serum gastrin levels have ranged from 140 to $240 \mathrm{pg} / \mathrm{ml}$ while on that drug. She remains asymptomatic 1 year after her operation.

Comments. Additional family history revealed that several members had peptic ulcer disease and have proved to have ZES as a component of MEN-I. In this case, as is typical of many MEN-I patients, the tumor in the tail of the pancreas did not secrete gastrin. However, this patient did have gastrin-secreting tumors in both the duodenum and the uncinate process of the pancreas. Because the patient has been reluctant to discontinue omeprazole, it is difficult to determine if she has residual tumor because patients on this drug frequently have gastrin levels in the range of 100 to $250 \mathrm{pg} / \mathrm{ml}$. This patient emphasizes that, regardless of the pancreatic findings in MEN-I patients, the duodenum must also be explored because of the high likelihood of additional small tumors in the duodenal wall.

\section{Case 6}

A 45-year-old man was originally diagnosed as having peptic ulcer disease and hypergastrinemia in 1981 while being evaluated for dysphagia. He was found to have esophagitis with a stricture and was placed on cimetidine to control the hyperacidity. During the last 2 years, he had developed diarrhea and increasing abdominal pain. He had been placed on omeprazole, which controlled the symptoms. He was then transferred to the UMMC for further evaluation. Studies confirmed that he had hypergastrinemia with levels of 2000 to $3000 \mathrm{pg} / \mathrm{ml}$. An angiogram showed a tumor blush in the mid-body of the pancreas, and TSVS and SASI regionalized the source of gastrin to the area of the pancreatic head or duodenum. Additional studies revealed hypercalcemia (calcium $10.7 \mathrm{mg} / \mathrm{dl}$ ), an elevated intact serum parathyroid hormone (PTH) level, and hyperprolactinemia. A diagnosis of the MEN-I syndrome was made and the patient started on bromocriptine to shrink a pituitary tumor that was readily identified on CT scan. One month later, a neck exploration was performed for the hyperparathyroidism, and a subtotal parathyroidectomy wa: performed in addition to a thymectomy to eliminate possible supernumerary glands. Under the same anesthesia, an exploratory celiotomy was carried out, and the pancreatic tumor seen on the angiogram was readily identified in the body of the pancreas (Fig. 6). After further mobilization of the pancreas, a $5 \mathrm{~cm}$ lymph node posterior to the head of the pancreas was identified and excised; it was shown to contain metastatic neuroendocrine tumor. After performing a distal pancreatectomy, duodenotomy was performed and three submucosal neuroendocrine tumors were palpable in the first, third, and fourth portions of the duodenum. The small lesions in the more proximal duodenum were locally excised, but the one in the fourth portion was large enough that a wedge excision of a portion of the duodenal wall was necessary through a second duodenostomy. Immunohistochemical studies showed that the duodenal tumors were positive for gastrin, as was the metastatic lymph node, but the tumor in the body of the pancreas contained no gastrin. Although his serum gastrin level fell to $67 \mathrm{pg} / \mathrm{ml} 4$ weeks after his operation, it rose to $600 \mathrm{pg} / \mathrm{ml}$ with secretin stimulation. Three months after operation, his serum gastrin was $197 \mathrm{pg} / \mathrm{ml}$ while on omeprazole $20 \mathrm{mg} /$ day. One year after his operation he is asymptomatic but continues to take omeprazole $20 \mathrm{mg}$ once a day; his most recent basal serum gastrin level while on this drug was $355 \mathrm{pg} / \mathrm{ml}$.

Comments. It is difficult to determine why this patient, who was diagnosed with ZES 10 years before being evaluated at the UMMC had not been evaluated further for MEN-I syndrome or surgically explored. Because of the untreated hyperparathyroidism, it was elected to treat this abnormality first and, if all went well, then proceed with abdominal exploration. Again, it should be noted that the predominant tumor in the body of the pancreas was negative on immunohistochemical study for gastrin. The fact that this patient had three primary neuroendocrine tumors in the duodenum is not unusual in MEN-I patients. The patient has not been cured biochemically as determined by secretin stimulation studies, but basal serum gastrin levels, when he is not on omeprazole, have been in the normal range. Whether he has another microadenoma in the duodenum or an overlooked metastatic lymph node cannot be determined at this time. 


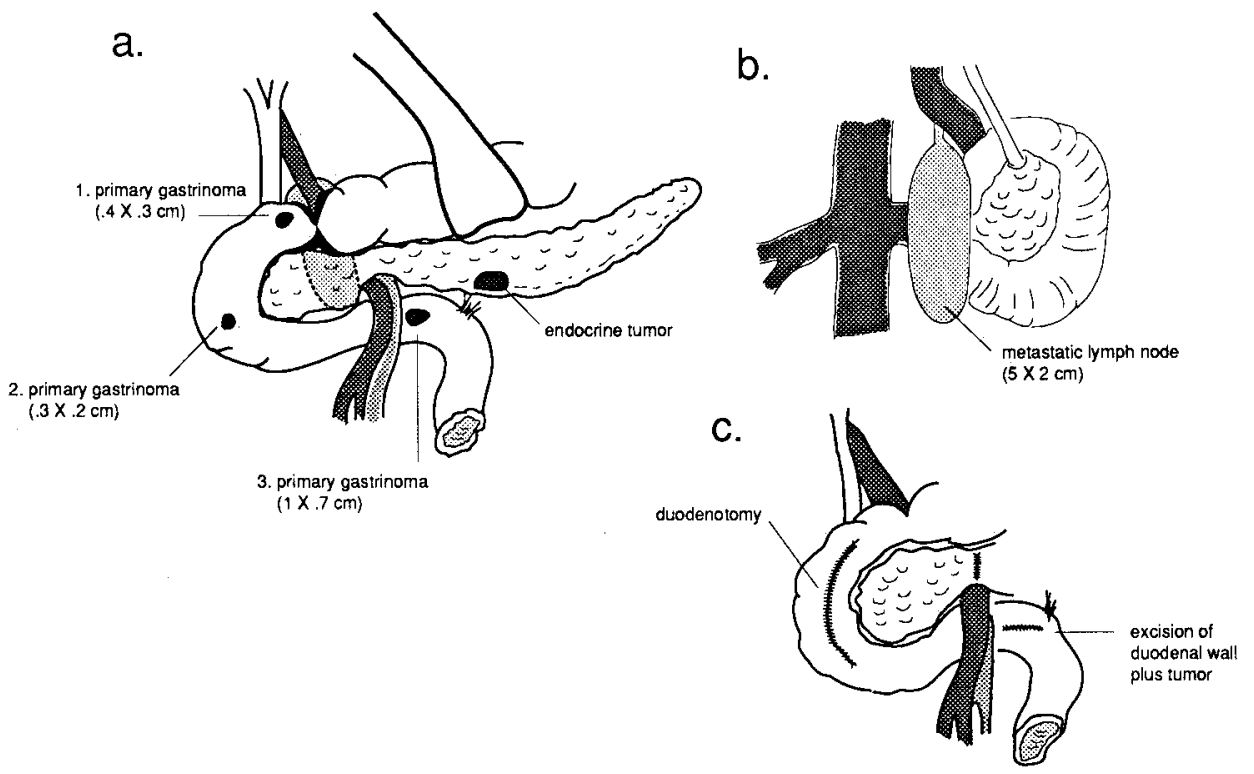

Fig. 6. Case 6: MEN-I in a 45-year-old man.

\section{Case 7}

A 46-year-old man with a 10-year history of "hyperactive bowel syndrome" primarily manifested by diarrhea, presented to an outside hospital with a perforated duodenal ulcer and underwent celiotomy and Graham patch. Five days later, he reperforated; and at exploration he was found to have a $3 \mathrm{~cm}$ ulcer in the second portion of the duodenum that was treated by primary closure and a proximal defunctioning gastrostomy tube. Seven days later, while recovering in the intensive care unit, he developed acalculous cholecystitis, and at a third operation a gangrenous gallbladder was excised. He developed multiple organ system failure and was maintained on total parenteral nutrition and life support for 5 weeks. After his subsequent recovery, he was transferred to another hospital where ZES was diagnosed after basal serum gastrin levels of $3000 \mathrm{pg} / \mathrm{ml}$ were obtained. A secretin stimulation study demonstrated a rise to $7000 \mathrm{pg} / \mathrm{ml}$. He was also found to have esophagitis and an esophageal stricture that required treatment with repeated dilatations. He was treated with omeprazole 20 mg qid and sandostatin, which controlled the diarrhea and abdominal pain. He was then transferred to the UMMC, where laboratory studies confirmed the diagnosis of ZES. He was also found to have an elevated serum calcium level of $11.6 \mathrm{mg} / \mathrm{dl}$ and an elevated serum PTH level. A diagnosis of MEN-I syndrome was established. He underwent SASI, which regionalized gastrin secretion to the head of the pancreas.

With these findings, he underwent a neck exploration and subtotal ( 3.5 glands excised) gland parathyroidectomy as well as thymectomy. Under the same general anesthetic, abdominal exploration was performed, and a large subserosal perigastric abscess was found near the site of his gastrostomy tube (Fig. 7). A $3 \mathrm{~cm}$ neuroendocrine tumor was found in the body of the pancreas, and a distal pancreatectomy and splenectomy were performed. On further exploration of the region of the head of the pancreas, a $1 \mathrm{~cm}$ peripancreatic lymph node was found on the posterior surface of the head of the pancreas next to the duodenum. It was positive on frozen section for metastatic neuroendocrine tumor. A duodenotomy was performed, and a
$0.15 \mathrm{~cm}$ submucosal neuroendocrine tumor was removed from the second part of the duodenum. Both the duodenal and peripancreatic lymph node neuroendocrine tumors stained positive for gastrin; however, the tumor in the body of the pancreas stained only for somatostatin and glucagon. Postoperatively, the patient's course was complicated by gastric outlet obstruction secondary to reaccumulation of the perigastric abscess that was successfully treated by percutaneous drainage and antibiotic therapy. Because of the esophageal stricture, he was continued on omeprazole $20 \mathrm{mg}$ at bedtime and periodic dilatations. His most recent serum gastrin level while on omeprazole was $185 \mathrm{pg} / \mathrm{ml}$. The gastrostomy tube was removed 4 months postoperatively after it was determined the patient could eat solids without dysphagia. He has subsequently gained 25 pounds, has returned to work, and is currently being evaluated for possible discontinuance of the omeprazole therapy.

Comments. This patient, who had a 10-year history of diarrhea without evaluation of serum gastrin, developed life-threatening complications from ZES syndrome; and although the diagnosis of ZES was subsequently established, the diagnosis of the MEN-I syndrome was not made until 6 months later when he was referred to the UMMC. Because of untreated hyperparathyroidism, it was elected to perform parathyroidectomy followed by abdominal exploration. Once again, the largest tumor in this patient's MEN-I pancreas was negative for gastrin, and the source of his ZES was a microgastrinoma with a metastatic peripancreatic lymph node.

\section{Discussion}

It has been appreciated only during the past few years that many of the duodenal gastrinomas were too small and submucosally located to be detected by preoperative endoscopy, palpation, or intraoperative ultrasonography [4]. Additionally, even tumors as small as 1 to $2 \mathrm{~mm}$ have proved to be associated with regional lymph node metastases. The fact that some patients were cured of hypergastrinemia years after a gastrec- 

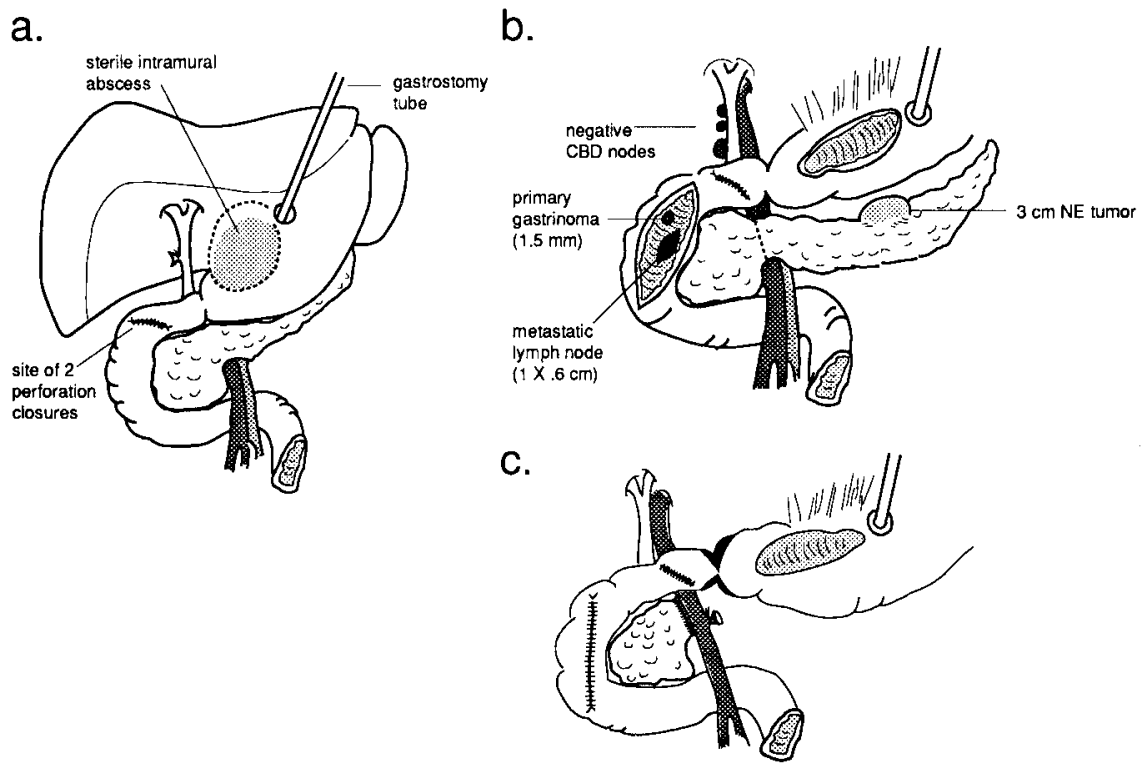

Fig. 7. Case 7: MEN-I in a 46-year-old man.

tomy, when they were explored and a single lymph node containing gastrinoma was excised, led some to the concept of "primary lymph node gastrinoma" [9, 12]. The current evidence suggests that it is much more likely that these patients had overlooked primary duodenal microgastrinomas that were excised with their gastrectomy specimens, which did not include the involved node(s).

From our experience, it is now clear that if the patient with sporadic ZES has no evidence of a pancreatic tumor after a complete exploration, the entire duodenum, from pylorus to the ligament of Treitz, must be carefully evaluated. In addition, any peripancreatic or periduodenal lymph node(s) that are abnormal in size or consistency should be excised and sent for frozen section study. A metastatic lymph node may be helpful in determining the most appropriate location for a duodenotomy when no tumor is palpable. If, after these maneuvers, no tumor has been found in the pancreas, lymph nodes, or duodenum, we now consider duodenotomy an essential part of a complete exploration for the ZES.

We perform an anterior longitudinal duodenotomy approximately $6 \mathrm{~cm}$ in length in the second part of the duodenum, after which an intraluminal digital examination from the antrum to the fourth portion of the duodenum is done. If no submucosal tumor is palpable, the mucosa is everted and palpated meticulously in a circumferential fashion in order to detect tumors as small as 1 to $2 \mathrm{~mm}$ underneath the mucosa. Tumors smaller than $4 \mathrm{~mm}$ in diameter are usually locally excised with a partial thickness of mucosa, tumor, and submucosa; and the site is closed from within with a few interrupted stitches. Most tumors that are $0.5 \mathrm{~cm}$ or larger are locally invasive in the submucosa and should be removed by excision of a full-thickness ellipse of duodenal wall with a margin around the tumor [8]. Because the larger lesions can usually be palpated, a duodenotomy can be planned so the excisional site can be included in the duodenotomy closure rather than having to close a second duodenotomy. In most cases, the duodenotomy has been closed with a full-thickness running absorbable suture and a second layer of interrupted silk sutures. Once this step has been completed, any remaining lymph nodes, regardless of size, in the drainage area of the tumor are excised.

Previous reports have shown an incidence of malignancy as defined by regional lymph node involvement, ranging from $30 \%$ to $60 \%$. In our group of patients, $100 \%$ were malignant, including one patient whose primary tumor was only $0.15 \mathrm{~mm}$ in diameter. As a result, we consider all duodenal tumors to be associated with lymph node involvement unless proved otherwise.

Although our approach to these malignant duodenal gastrinomas has been conservative in terms of avoiding pancreaticoduodenectomy, the results thus far have been gratifying. Only long-term follow-up will determine whether patients currently biochemically "cured" will remain so, although we have already accumulated a small group who have maintained normal gastrin levels for more than 5 years. Furthermore, Oberhelman's long-term results after excisional therapy of duodenal gastrinomas, five of which were malignant, showed that an excellent initial result was sustained for 2 to 11 years [2]. In his series, 7 patients were treated with local excision, and 3 had pancreaticoduodenectomies with one postoperative death. His patients were all treated during the era before effective drug therapy was available to control gastric hyperacidity. We have intentionally avoided pancreaticoduodenectomy and its potential morbidity because omeprazole can effectively control gastric acid should conservative surgical excisions fail.

Our approach to the MEN-I patients with ZES is based on the fact that the source of gastrin in these patients is from discrete tumors rather than from islet cell hyperplasia and nesidioblastosis, which are consistent findings in the MEN-I pancreas [13]. Many of these patients have additional neuroendocrine tumors in the body or tail of the pancreas that may secrete other hormones or be malignant. We previously selected operative candidates based on TSVS but currently consider that all MEN-I patients should be explored unless liver metastases have been demonstrated by CT scan or angiography. Our experience suggests that most but not all MEN-I patients have gastrinomas within the gastrinoma triangle [11]. These lesions 
are most likely to be in the duodenum but may be present in both duodenum and pancreatic head [7]. Because duodenal tumors in MEN-I patients are often small and multiple, a duodenotomy and complete exploration from the pylorus to the ligament of Treitz is necessary in all patients. All peripancreatic and periduodenal lymph nodes should be excised because the incidence of microscopic metastases is at least $60 \%$ and may be even higher. In this current group of patients, all three had grossly apparent lymph node metastases. Any tumors palpable in the head or uncinate process of the pancreas should be enucleated. Although intraoperative ultrasonography may be useful in this regard, most gastrin-secreting neuroendocrine tumors arising in the pancreas are $1 \mathrm{~cm}$ or larger in diameter and are readily palpable $[11,14]$. Our emphasis on performing a distal pancreatectomy is based on the fact that in each of our previous cases and in those in the present series all had at least one or more discrete neuroendocrine tumors in the body or tail. Although the results in the MEN-I ZES patients are unlikely to be uniformly successful, it is our belief that many of these patients can be rendered eugastrinemic, providing their procedures are completed as described. Furthermore, the chances of developing other neuroendocrine syndromes or hepatic metastases should be significantly reduced.

\section{Résumé}

Des études récentes ont démontré que les gastrinomes primitifs étaient localisés au duodénum dans 30 à $40 \%$ des cas, beaucoup plus fréquemment que communémment admis. La découverte de ces tumeurs reste souvent difficile par des investigations conventionelles et nécessitent une duodénotomie avec une exploration et une palpation méticuleuses de la muqueuse duodénale éversée. D'aussi petites tumeurs que de 1 ou de 2 mm peuvent être accompagnées de métastases ganglionnaires. Sept cas de gastrinomes duodénaux, traités en deux ans, sont étudiés. Quatre avaient un syndrome de Zollinger-Ellison (SZE) et trois avaient un syndrome MEN-I. Tous ces patients avaient un gastrinome malin car tous avaient des métastases ganglionnaires et dans un cas, des métastases hépatiques. En cas de SZE sporadique, une eugastrinémie a été obtenue par excision de la tumeur, associée à une lymphadénectomie et, dans un cas, à une lobectomie hépatique. Deux des trois patients ayant un syndrome MEN-I sont devenus eugastrinémiques après des interventions similaires associées dans un cas à une pancréatectomie distale. La duodénotomie est un geste essentiel dans le cas d'un SZE sporadique lorsqu'on ne retrouve pas de tumeur, et chez tous les patients ayant un syndrome $\mathrm{MEN}$, quelle que soient les données pancréatiques. La lymphadénectomie régionale est également importante en cas de tumeur duodénale.

\section{Resumen}

Estudios recientes han demostrado que el duodeno es un lugar más común (30-40\%) de ubicación de gastrinomas primarios de lo que había sido previamente reportado.

Estos tumores frecuentemente están ocultos en la exploración convencional y requieren duodenotomía y meticulosa evaluación de la mucosa por eversión y palpación directa para su detección. Además, tumores pequeños, de 1 y $2 \mathrm{~mm}$, pueden estar asociados con metástasis ganglionares. Se informan 7 casos adicionales de gastrinomas duodenales tratados en un periodo de dos años. Cuatro tenían síndrome de ZollingerEllison esporádico (SZE) y tres síndrome de NEM-1. Todos los 7 pacientes tenían gastrinomas duodenales malignos comprobado por la presencia de ganglios linfáticos metastásicos y, en un caso, también una metástasis hepática grande. La resección local del tumor, la disección de los ganglios y, en un caso, la lobectomía hepática, resultaron en eugastrinemia en los cuatro pacientes con SZE. Dos de los tres con SNEM-1 también aparecieron eugastrinémicos luego de procedimientos similares y la adición de pancreatectomía distal.

La duodenotomía es considerada un procedimiento esencial en pacientes con SZE esporádico cuando no se encuentra tumor pancreático, en todos los pacientes con SNEM-1 SZE, no importa cuales sean los hallazgos en el páncreas. La resección de los ganglios regionales también es esencial en presencia de tumor duodenal.

\section{References}

1. Oberhelman, H.A., Jr., Nelson, T.S.: Surgical consideration in the management of ulcerogenic tumors of the pancreas and duodenum. Am. J. Surg. 108:132, 1964

2. Oberhelman, H.A., Jr.: Excisional therapy for ulcerogenic tumors of the duodenum: long term results. Arch. Surg. 104:447, 1972

3. Howard, T.J., Zinner, M.J., Stabile, B.E., Passaro, E.P.: Gastrinoma, excision for cure: a prospective analysis. Ann. Surg. 211:9, 1990

4. Thompson, N.W., Vinik, A.I., Eckhauser, F.E.: Microgastrinomas of the duodenum: a course for failed operations of the ZollingerEllison syndrome. Ann. Surg. 209:396, 1989

5. Sheppard, B.C., Norton, J.A., Doppman, J.L., Maton, P.N., Gardner, J.D., Jensen, R.T.: Management of islet cell tumors in patients with multiple endocrine neoplasia: a prospective study. Surgery 106:1108, 1989

6. Vinik, A.I., Moattari, A.R., Cho, K., Thompson, N.W.: Transhepatic portal vein catheterization for localization of sporadic and MEN-I gastrinomas: a ten year experience. Surgery 107:246, 1990

7. Pipeleers-Marichal, M., Somers, G., Willems, G., et al.: Duodenal gastrinomas as the source of hypergastrinemia and ZollingerEllison syndrome in patients with MEN-I. N. Engl. J. Med. $322: 723,1990$

8. Donow, C., Pipeleers-Marichal, M., Schroder, S.: Surgical pathology of gastrinoma: site, size, multicentricity, association with multiple neoplasia type I and malignancy. Cancer 68:1329-1334, 1991

9. Delcore, R., Cheung, L.Y., Friesen, S.R.: Outcome of lymph node involvement in patients with the Zollinger-Ellison syndrome. Ann. Surg. 208:291, 1988

10. Stabile, B.E., Morrow, D.J., Passaro, E.P.: The gastrinoma triangle: operative implications. Am. J. Surg. 147:25, 1984

11. Thompson, N.W., Bondeson, A.G., Bondeson, L., Vinik, A.I.: The surgical treatment of gastrinoma in MEN-I syndrome patients. Surgery 106:1081, 1989

12. Thompson, N.E., Vinik, A.I., Eckhauser, F.E., Strodel, W.E.: Extrapancreatic gastrinomas. Surgery $98: 1113,1985$

13. Thompson, N.W., Lloyd, R.B., Nishiyama, R.H., et al.: MEN-I pancreas: a histological and immunohistological study. World $\mathbf{J}$. Surg. 8:561, 1984

14. Norton, N.W., Cromack, D.T., Shawker, T.H.: Intraoperative ultrasonographic localization of islet cell tumors: a prospective comparison to palpation. Ann. Surg. 207:160, 1988 